\title{
Implementing recommendations arising from confidential enquiries into maternal deaths
}

\author{
Robert Clive Pattinson MD, MRCOG, FCOG (SA) \\ Director, MRC Maternal and Infant Health Care Strategies Research Unit and Clinical Head, \\ Obstetrics and Gynaecology Department, University of Pretoria, South Africa \\ Anne-Marie Bergh PhD \\ Senior Researcher, MRC Maternal and Infant Health Care Strategies Research Unit and Head, \\ Education Office, Faculty of Health Sciences, University of Pretoria, South Africa
}

\begin{abstract}
Implementing recommendations is a complex process involving all levels of health care. Effecting change in the health system can be broadly divided into four areas: policy, administration, clinical practice and training. Changes at the policy level require advocacy by lobby groups, as these changes are mainly political in nature. Changes at administrative level require a diversion of resources, and a clear policy framework must be in place within which the health administrator can work. Changes to clinical practice refer mainly changes in protocols of managing patients. The essential elements to change clinical practice include on-site, face-to-face teaching by a senior clinician; ineffective methods are lectures and memorandums on guidelines for practice posted to clinicians. Training refers to ensuring there are appropriate curricula for healthcare workers. Recommendations should also be phrased in such a way that targets can be established. These targets should be measurable and then be measured.
\end{abstract}

Key words: change management; confidential enquiries into maternal deaths; implementation of recommendations

\section{Introduction}

Evidence-based knowledge does not necessarily lead to policy.

Policy does not necessarily lead to implementation.

Implementation does not necessarily lead to sustainable practice.

Implementation of recommendations arising from confidential enquiries into maternal deaths is essential if these enquiries are to have any meaningful effect. These recommendations are based on reducing the common causes of maternal deaths. In 2000, 189 countries set Millennium Development Goals (MDG), the fifth of which was to reduce the maternal mortality ratio (MMR) by three-quarters 
by 2015. A broad consensus about the appropriate strategies exists and a growing body of data and tested tools are available to help reduce the MMR. ${ }^{1}$ In other words, we know what needs to be done; the problem lies in getting it done. Recommendations from confidential enquiries would presumably have taken into consideration the strategies available and tailored them to their individual country or provincial needs. This review examines factors involved in implementing these recommendations, namely, making change happen.

\section{What is change?}

\section{Assumptions about change}

Policy makers often assume that the change process of translating knowledge of the causes of maternal deaths into improvement and sustaining of best practice (i.e. the reduction of the causes of death) is a simple, linear process that should take place automatically. This is illustrated well by a study done in a rural area of South Africa. It was based on the simple hypothesis that the completion of a specific perinatal training programme aimed at improving knowledge would also improve the quality of obstetric care. However, although there was a very significant improvement of knowledge of participants, the quality of care actually deteriorated. $^{2}$

Similarly, it is often assumed that publishing recommendations based on the knowledge of the causes of maternal deaths will lead to improved practice and eventually a reduction in maternal mortalities. Recommendations are by nature very general statements. Critical to the success of their implementation would be accompanying statements clearly indicating roles and responsibilities with regard to action, the choice of appropriate strategies and the achievement of very specific targets. Finally, the creation of recommendations is meaningless unless their implementation is monitored and evaluated. This is well demonstrated by the finding that very few of the recommendations on reducing maternal deaths in South Africa made in previous reports had been implemented. For example, only one of nine provinces achieved the modest goal of half of ambulances arriving at the site within 1 hour of being called. This was mostly due to shortages in emergency services vehicles and personnel and the centralization of emergency services. $^{3}$

\section{An ecological approach to change}

The conceptual framework for this chapter is based on reviews of the theory and research in organizational change. The most difficult part in any change process is the translation of recommendations emanating from knowledge on maternal causes of death into actions of implementation that are institutionalized to such a degree that the continuous adaptation to current best practice becomes a sustainable prospect. When an ecological approach to organizational change is used, recommendations are not seen as inputs into a machine (the health 
system or healthcare facility) that will result in readily predictable outputs, namely the implementation of recommendations and an improvement in the health service. Instead, the health system as a whole, and each healthcare facility, is seen as a network of complex organizational interactions, with results that are often unpredictable. Implementing recommendations means change that will affect the whole system or organization, not just one segment. Changing one aspect might mean changing many other aspects. Therefore, a process of change involves all levels of a health system, various facets of service provision, as well as the diversity of role-players, from policy makers to clinicians to other health professionals working at the grassroots. It involves changing, on the one hand, aspects of the system or organization itself and, on the other hand, the behaviour of individuals or groups of people working in that organization.

Figure 1 is a graphic depiction of the interplay between knowledge, policy, implementation and the sustaining of practice, which is viewed as a complex, cyclical set of ever-changing interactions between role-players at different levels who might need to change their own behaviour and that of those under their supervision. This behaviour is not only related to skills and clinical practice, but to a variety of other actions and styles encompassing administration, management, leadership, motivation and attitudes enabling the change to take place. To quote Van Lerberghe and De Brouwere ${ }^{4}$, maternal deaths are often the result of "Too little, too late, too sloppy: delivery care is not a mere matter of having a hospital and trained clinicians, it is also a question of how professional staff behave." Furthermore, all role-players work within spaces (i.e. physical, economic and political environments) in which there are external and internal forces or factors that either facilitate or hinder the implementation of recommendations. ${ }^{5-7}$ This dynamics is often referred to as the "organizational climate".

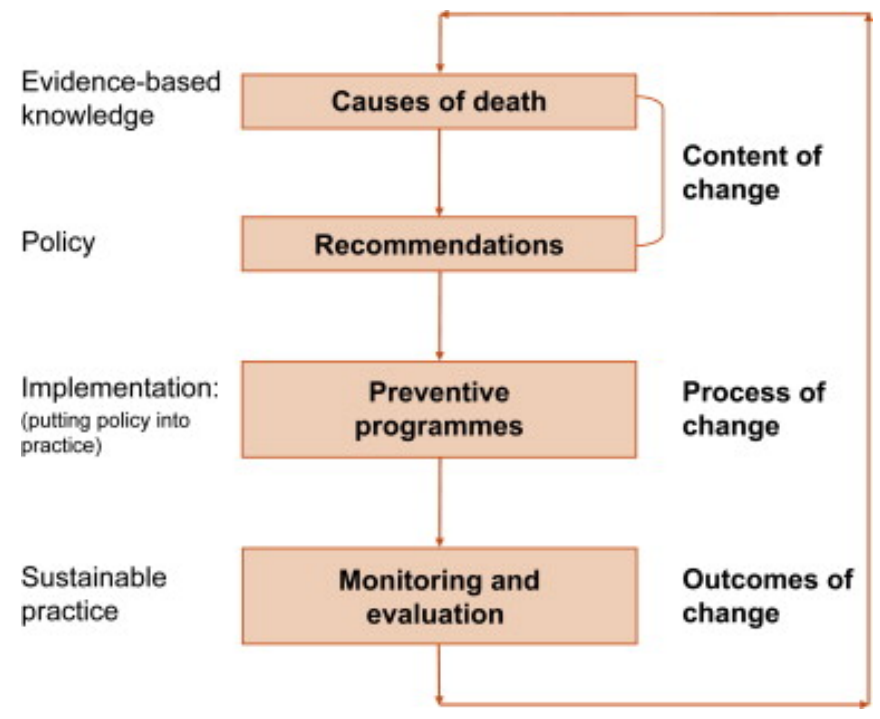

Figure 1. The interplay between knowledge, policy, implementation and sustainable practice. 


\section{The nature of change}

In their review of the theory and practice of organizational change, Armenakis and Bedeian ${ }^{10}$ make a distinction between content, context, process and outcomes of change (see Figure 1). Translated into the implementation of recommendations emanating from confidential enquiries, the results of a confidential enquiry (causes of maternal death) as well as the recommendations (policy) could be considered as the content of change. The nature of this content could be improvements in health services, such as speeding up access to services, service development and improved quality of care. It could also be introducing new procedures or therapies. ${ }^{11}$ The context of change refers to the internal and external forces that facilitate or hinder the implementation of recommendations. The process of change comprises the preventive programmes and actions plans that are put in place for implementation. The process of change also involves the choice of strategies for getting things done (Figure 2). The outcome of change would be a reduction in maternal mortality (i.e. reaching the MDG). For this reduction to be sustained, a monitoring and evaluation system needs to be in place. Outcome of change could also include a change in staff attitudes and overcoming staff resistance to implementing recommendations.

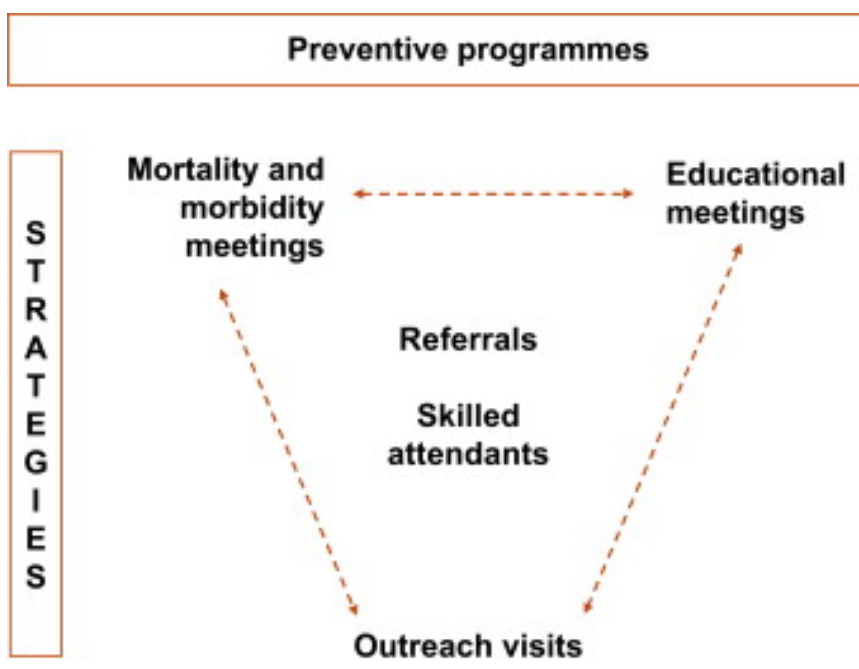

Figure 2. Main clinical strategies for implementing recommendations arising from confidential enquiries into maternal deaths.

\section{Agents of change}

When the implementation of the recommendations following a confidential enquiry into maternal deaths is seen as a change process, all members of a 
health system could be considered as agents of change (Figure 3 ). For this review, a distinction is made between the 'enablers' of the change process and the 'doers'. The enablers are the managers (including clinicians and nonclinicians) who should ensure that policies are in place, that resources are present (e.g. transport, staffing, equipment, blood) and that various training programmes take place. The clinicians - the doers - include members of various professions, such as medical practitioners, obstetricians, midwives and primary healthcare professionals. They are responsible for doing the clinical work, which includes outreach and training. One of the determinants of successful implementation is effective communication ${ }^{12}$ between individual and groups of change agents at the various institutional and health-system levels, ranging from how this is done in a maternity unit of a healthcare facility to what happens at a particular country's Ministry of Health.

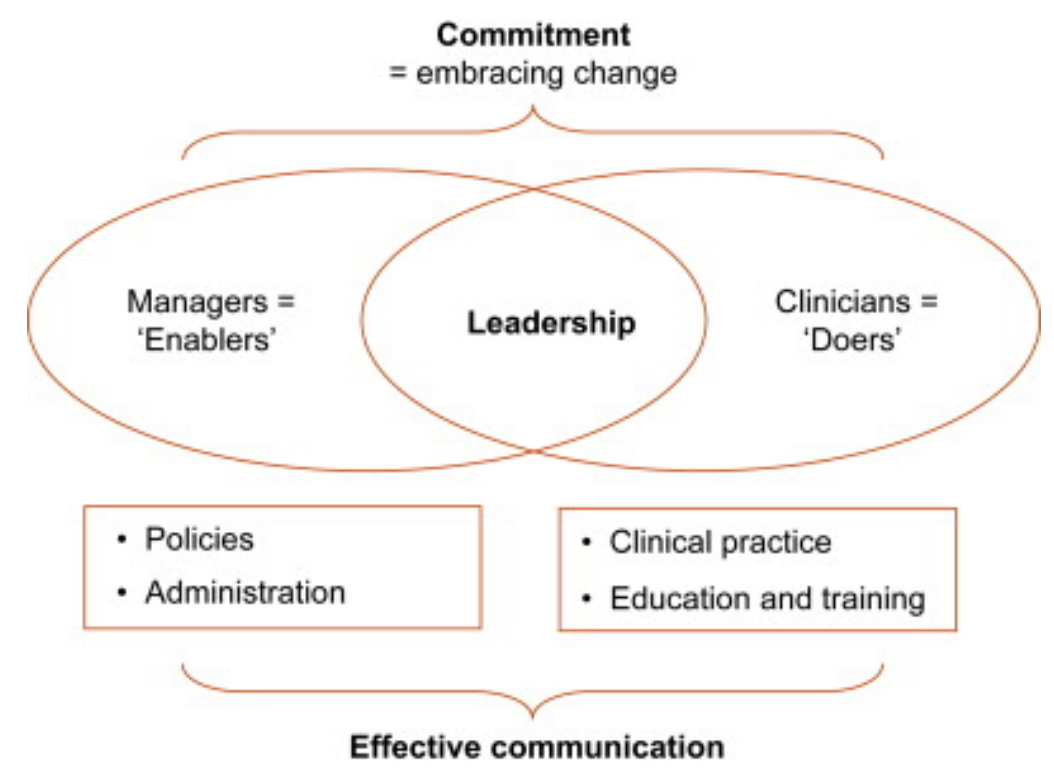

Figure 3. Roles and responsibilities of managers and clinicians as agents of change.

\section{Areas of change}

Broadly, there are four areas where changes in the health system can be effected: policy (those that require political decisions for structural changes in the health system), administration (those that require local administrative decisions to shift resources to be effective), clinical practice (those that require changes to clinical practice) and pre-service education and training (those that require changes to the training of healthcare workers) (see Figure 3). The way in which recommendations and proposed strategies is phrased should indicate in which of the above areas action is needed. Recommendations should also be phrased in such a way that targets can be established, and these targets should be 
measurable. Furthermore, there should be a clear allocation of responsibilities for each action, thereby introducing accountability.

The enablers or managers of change are mainly responsible for the areas of policy and administration, whereas the doers or clinicians are responsible for the areas of clinical practice and education and training. A condition for the successful implementation of recommendations is leadership and commitment among managers and clinicians.

\section{Policy}

Confidential enquiries into maternal deaths identify the causes of deaths and indicate what in the health system needs to be modified. Some of the components needing modification can be very fundamental, such as lack of skilled birth attendants. Clinicians are not able to solve problems that are so fundamental; they are the responsibility of a country's Ministry or Department of Health. For example, Thailand had maternal mortality levels above 400/100,000 live births. The Thai Department of Health gave priority to the training of paramedical personnel in their first three health plans (1961-1976) and to increasing the numbers of newly registered midwives. The mortality halved to 200-250/100,000 live births in 1970. Midwives became the key figures in villages and, by 1980 , the MMR was $98 / 100,000$ live births. The next health plans concentrated on strengthening and equipping district hospitals. By 1985 the mortality had halved again to 42/100,000 live births; in 1990 it was 25/100,000 live births and in $199511 / 100,000$ live births. ${ }^{13,14}$ Clearly, a political commitment is necessary. ${ }^{11}$ It could also be argued that there is a need for transformational leaders who have a transcendent vision and carry it through despite lack of consensus and attacks on their leadership. ${ }^{15}$

Advocacy is a pivotal element in the interface between enablers and doers. Although the MDG is an important motivator for governments, advocacy by clinicians on behalf of pregnant women, especially through their professional organizations, is crucial. Ross ${ }^{16}$ regards advocacy by communities and organizations with an understanding and experience of health issues as the most important element for creating policy change. With regard to obstetriciangynaecologists, Gasman et al (p. 311) ${ }^{17}$ comment as follows:

As a professional group and also as individuals, ob-gyns are in a unique position to support and advocate for women. Ob-gyns can speak with credibility about the health needs of women and the clinical interventions that can save lives and protect women's health. Moreover, they have significant social capital resources, social connections, and expertise - all of which often allow them privileged access and special influence with policymakers and other elite groups, as well as the media and other health professions. 
Whereas professional advocacy should be directed at policy makers, advocacy for demanding improved maternity services should also be directed at the general public. ${ }^{18}$

\section{Administration}

Having the policy in place does not mean that change will occur. The adoption of the Choice of Termination of Pregnancy Act of 1996 in South Africa is such an example. This act liberalized the abortion laws; however, the number of maternal deaths 1999-2001 and 2002-2004 reported to the National Committee for Confidential Enquiries into Maternal Deaths reduced only slightly. ${ }^{19}$ An epidemiological survey by Jewkes et al showed no reduction in deaths and a non-significant shift from more severe to less severe cases when comparing 1994 and $2000 .^{20}$ In examining the progress of implementing the recommendation of improving access to Termination of Pregnancy services, less than half the provinces had achieved their targets. ${ }^{3}$ However, in areas where there were adequate services there had been a drop in maternal deaths due to complications of abortion. ${ }^{21}$

Health administrators are responsible for diverting adequate resources, both physical and human, to implement the policy, but this has not occurred widely. Holding health administrators accountable for implementing policy by incorporating the targets into their key performance areas is one method of trying to encourage change. Performance appraisal systems could be seen as a mechanism to promote employee commitment. Certain forms of commitment or loyalty have been shown to have a positive effect on work performance, for example commitment to supervisors and to a lesser extent to the organization. ${ }^{22}$

\section{Clinical practice}

There is a growing body of research on strategies for improving the quality of care developing in this previously neglected area. Traditional methods of implementing new evidence-based guidelines have been by sending memorandums to hospitals or clinicians or publishing them in medical journals. These have been shown to be uniformly ineffective in improving the quality of care. ${ }^{23}$ Maternal morbidity and mortality meetings at health institutions are another traditional method implementing new guidelines, but this audit and feedback has been surprisingly mostly ineffective.

\section{Mortality and morbidity meetings}

The basic assumption of these meetings is that once the problems have been identified and made known to the health professionals there will be a selfcorrection in behaviour and the quality of care will improve. In a systematic review on audit and feedback, Jamtvedt et $\mathrm{al}^{24}$ found only a small positive effect. 
Jamtvedt et al investigated the various types of intervention (audit and feedback alone, audit and feedback with educational meetings, or multifaceted interventions that included audit and feedback), the intensity of the audit and feedback, the complexity of the targeted behaviour, the seriousness of the outcome, baseline compliance and study quality. ${ }^{24}$ They found the effect was more likely to be larger when the baseline adherence to recommended practice was low, and when audit and feedback is provided more intensively (i.e. to an individual, by a senior colleague or supervisor, verbally over a period of more than a month) with or without educational meetings; no other effect could be detected. They further postulated that the effects of audit and feedback might be greater if the health professionals were actively involved and had specific and formal responsibilities for implementing change.

Morbidity and mortality meetings usually form part of clinical governance and health professionals are usually required to be involved in some way. As these meetings take place anyway, it is worth taking some effort to ensure they are effective. The areas of feedback that have been shown to be effective are:

- Senior person to conduct present feedback

- Continue feedback sessions over a long period

- Face-to-face report back to individuals is most effective

- Combine with educational meetings

\section{Continuing medical education}

Most healthcare professionals spend time at educational meetings, many of which are required as a means of retaining their licence to practice. O'Brien et $\mathrm{al}^{25}$ performed a systematic review of the different types of educational meetings and workshops to identify those that are most effective in improving clinical care. They found that interactive workshops were most likely to improve professional practice, whereas lectures alone were unlikely to change professional practice.

\section{Outreach visits}

O'Brien et $\mathrm{al}^{26}$ reviewed the value of educational outreach visits and found that they appeared to be a promising approach to modifying health professional behaviour. All these outreach visits consisted of several components such as lectures, conferences and written materials. They mentioned that the cost effectiveness is not known.

In many health systems, specialists visit primary care or rural hospitals, mainly to reduce referrals and to improve the access of these patients to specialist care. 
Gruen et $\mathrm{al}^{27}$ reviewed their effect and concluded that specialist outreach can improve access, outcomes and service use, especially when delivered as part of a multifaceted intervention involving case conferences, joint consultations, seminars and educational sessions, other health professionals or other care enhancements. Again the information on cost was not available for review.

The costs of outreach can be considerable and determining the most effective way to perform it must take into consideration the site of training. Which is more cost-effective, on-site facilitation or off-site hands on training in a centre of excellence? In a randomized trial, Bergh et $\mathrm{al}^{28}$ found that the site of training did not influence the success of implementing kangaroo mother care. The decision as to what to use would be dependent on the relative costs of a training team visiting a site versus the cost of a number health workers from various sites attending training at a centre of excellence. The geographical situation dictates the answer.

\section{Referrals}

In most health systems appropriate referral is key to ensuring the right patients see the right clinician at the right level of care. Grimshaw et $\mathrm{al}^{29}$ reviewed studies aimed at improving referral. They found that referral guidelines are more likely to be effective if: (1) local secondary care providers are involved in dissemination activities; (2) structured referral sheets are used; (3) secondary care management is responsive to changes in primary care behaviour as a result of the guidelines; and (4) they reflect local circumstances and address local barriers.

\section{Skills training}

Ensuring adequate skilled attendants at birth for pregnant women is the responsibility of the politicians and administrators; however, clinicians must see that these attendants are appropriately trained. It is essential that all healthcare workers managing women in labour, delivery and immediately thereafter are well versed in Emergency Obstetric Care (EOC). Basic EOC (BEOC) consists of six key functions: intravenous or intramuscular administration of antibiotics, oxytocic drugs, anticonvulsants; manual removal of the placenta; removal of retained products of conception and assisted vaginal delivery. Comprehensive EOC (CEOC) consists of the above plus the ability to provide caesarean section and blood transfusion. Training programmes that use mannequins to train healthcare workers in the necessary skills for BEOC and CEOC are available. The Royal College of Obstetricians and Gynaecologists has developed such a programme aimed at ensuring the necessary skills are available in developing countries. ${ }^{30} \mathrm{~A}$ more sophisticated programme - the Managing Obstetric Emergencies and Trauma (MOET) course - is available for developed countries. ${ }^{31}$ The use of mannequins to improve clinical skills is gaining popularity throughout the world. 


\section{Pre-service education and training}

It is clear that key recommendations regarding the reduction in maternal deaths should be part of the pre-service curricula of, for example, medical students and student nurses. Constant review of educational programmes needs to be undertaken by medical schools and licensing bodies, in partnership with Ministries or Departments of Health. It is imperative to reflect on whether students are appropriately trained and whether the appropriate topics are addressed.

\section{Summary}

It is often assumed that implementing recommendations to reduce maternal deaths means little more than ensuring guidelines are in place and used; this is far from the truth. Initiating and sustaining change is a complex process involving many structures in a health system and a variety of role-players, each of whom has to show commitment to change. The agents of change include both managers ('enablers') and clinicians ('doers').

Changing clinical practice cannot be seen in isolation of the other three areas of implementing recommendations, namely policy, administration and training. The principles of successful training programmes have been outlined, but much of the research has been in other disciplines. The costs, frequency of visits and sustainability of changes still need to be determined.

However, no matter how good the implementation of recommendations is, the attitude of health professionals will be crucial to their success. To quote Van Lerberghe and De Brouwere ${ }^{4}$, maternal deaths are often the result of "Too little, too late, too sloppy: delivery care is not a mere matter of having a hospital and trained clinicians, it is also a question of how professional staff behave".

- Outreach visits are most successful if carried out by a senior clinician, there is one-on-one tuition, and use multiple techniques such as workshops and printed material.

- Lectures and published articles on their own have very little effect on changing practice.

- Training packages and toolkits are available to improve knowledge and skills.

- Maternal morbidity and mortality meetings should be run by a senior clinician and be used as a continuing medical education opportunity.

- Testing of training packages and toolkits. 
- More trials in obstetrics - most of the literature comes from other specialities.

- Costing of outreach.

- Sustainability of programmes.

- Frequency of visits.

\section{Acknowledgements}

The authors would like to acknowledge the support of the Medical Research Council of South Africa. The views expressed are those of the authors.

\section{References}

1. A. Rosenfield, D. Maine and L. Freedman, Meeting MDG-5: an impossible dream?, Lancet 386 (9542) (2006), pp. 1133-1135.

2. E. Le Roux, R.C. Pattinson and W. Tsaku et al., Does successful completion of the Perinatal Education Programme result in improved obstetric care?, S Afr Med J 88 (1998), pp. 180-187.

3. L. Mangate, Progress made on implementation of recommendations from the Saving Mothers 1999-2001 report. In: R.C. Pattinson, Editor, Saving Mothers 2002-2004: Third Report on Confidential Enquiries into Maternal Deaths in South Africa, Government Printers, Pretoria (2006), pp. 305-321.

4. W. Van Lerberghe and V. De Brouwere, Reducing maternal mortality in a context of poverty. In: V. De Brouwere and W. Van Lerberghe, Editors, Safe Motherhood Strategies: a Review of the Evidence, ITG Press, Antwerp (2001), pp. 1-6.

5. J.F. Sallis and N. Owen, Ecological models of health behavior. In: K. Glanz, B.K. Rimer and F.M. Lewis, Editors, Health Behavior and Health Education: Theory, Research and Practice (3rd ed.), Jossey-Bass, San Francisco, CA (2002), pp. 462-484.

6. S. Fernandez and H.G. Rainey, Managing successful organizational change in the public sector: an agenda for research and practice, Publ Admin Rev 66 (2) (2006), pp. 168-176.

7. M. Tschirhart, Fernandez and Rainey: Managing successful organizational change in the public sector: an agenda for research and practice (commentary), Publ Admin Rev 66 (2) (2006), pp. 38-42.

8. A. Steckler, R. Goodman and M.C. Kegler, Mobilizing organizations for health enhancement: theories of organizational change. In: K. Glanz, B.K. Rimer and F.M. Lewis, Editors, Health Behavior and Health Education: Theory, Research and Practice (3rd ed.), Jossey-Bass, San Francisco, CA (2002), pp. 335-360. 
9. C. Perry, N. LeMay and G. Rodway et al., Validating a work group climate assessment tool for improving the performance of public health organizations, Hum Resour Health 3 (2005), p. 10.

10. A. Armenakis and A.G. Bedeian, Organizational change: a review of theory and research in the 1990's, J Manag 25 (1999), pp. 293-315.

11. A. Weeks, Maternal mortality: it's time to get political, BJOG 114 (2007), pp. 125-126.

12. L. Almeida Costa, J.A. De Matos and M.P.E. Cunha, The manager as change agent, Int Stud Manag Organ 33 (4) (2003), pp. 65-93.

13. W. Van Lerberghe and V. De Brouwere, Of blind alleys and things that have worked: history's lessons on reducing maternal mortality. In: V. De Brouwere and W. Van Lerberghe, Editors, Safe Motherhood Strategies: a Review of the Evidence, ITG Press, Antwerp (2001), pp. 7-33.

14. In: S. Wibulpolprasert, Editor, Thailand health profile 1997-1998. Ministry of Public Health, ETO Press, Bangkok (2000).

15. J.S. Bujah, Health care leaders as agents of change, Physician Exec (2005 May/June), pp. 38-40.

16. R.K. Ross, Advocacy and policy change, Health Aff 26 (2) (2007), pp. 593594.

17. N. Gasman, M.M. Blandon and B.B. Crane, Abortion, social inequity, and women's health: Obstetrician-gynecologists as agents of change, Int J Gynecol Obstet 94 (3) (2006), pp. 310-316.

18. P.F. Brussard and J.C. Tull, Conservation biology and four types of advocacy, Conserv Biol 21 (1) (2007), pp. 21-24.

19. E.J. Buchmann and M. Kunene, Early pregnancy deaths. In: R.C. Pattinson, Editor, Saving Mothers 2002-2004: Third Report on Confidential Enquiries into Maternal Deaths in South Africa, Government Printers, Pretoria (2006), pp. 96116.

20. R. Jewkes, H. Brown and K. Dickson-Tetteh et al., Prevalence of morbidity associated with abortion before and after legislation in South Africa, BMJ 324 (2002), pp. 1252-1253.

21. A.M. Mbele, R.C. Pattinson and L.C. Snyman, The impact of the Choice of Termination of Pregnancy Act on maternal morbidity and mortality in the west of Pretoria, S Afr Med J 96 (2006), pp. 1196-1198.

22. T.E. Becker, R.S. Billings and D.M. Eveleth et al., Foci and bases for employee commitment: implications for job performance, Acad Manage J 38 (1999), pp. 454-482.

23. J.M. Grimshaw, L. Shirran and R. Thomas et al., Changing provider behavior: An overview of systematic reviews of interventions, Med Care 39 (8) (2001), pp. II2-II45 Supplement 2.

24. G. Jamtvedt, J.M. Young and D.T. Kristoffersn et al., Audit and feedback: effects on professional practice and health care outcomes, Cochrane Database Syst Rev (Issue 2) (2006) Art. No.: CD000295.pub2.

25. M.A. O'Brien, N. Freemantle and A.D. Oxman et al., Continuing education meetings and workshops: effects on professional practice and health care outcomes, Cochrane Database Syst Rev (Issue 1) (2001) Art. No.: CD003030. 
26. M.A. O'Brien, A.D. Oxman and D.A. Davis et al., Educational outreach visits: effects on professional practice and health care outcomes, Cochrane Database Syst Rev (Issue 4) (1997) Art. No.: CD000409.

27. R.L. Gruen, T.S. Weeramanthri and S.E. Knight et al., Specialist outreach clinics in primary care and rural hospital settings, Cochrane Database Syst Rev (Issue 4) (2003) Art. No.: CD003798.

28. A.-M. Bergh, E. van Rooyen and R.C. Pattinson, 'On-site' versus 'off-site' facilitation: a randomised trial of outreach strategies, Proceedings: 25th

Conference on Priorities in Perinatal Care in Southern Africa, 7-10 March 2006, Champagne Sports Resort, Drakensberg, KZN, Priorities in Perinatal Care Association, Pretoria (2006), pp. 123-124.

29. J.M. Grimshaw, R.A.G. Winkens and L. Shirran et al., Interventions to improve outpatient referrals from primary to secondary care, Cochrane Database Syst Rev (Issue 3) (2005) Art. No.: CD005471.

30. N. Van den Broek, Life Saving Skills Manual: Essential Obstetric Care, RCOG Press, London (2006).

31. C. Cox, K. Grady and C. Howell, Managing Obstetric Emergencies and Trauma: The MOET Course Manual (2nd edn.), RCOG Press, London (2006). 